University of South Florida

DIGITAL COMMONS

Digital Commons @ University of

@ UNIVERSITY OF SOUTH FLORIDA

South Florida

Academic Resources Faculty and Staff

Publications

Tampa Library

December 2006

\title{
Untangling the Jungle of E-Journal Access Issues Using CRM Software
}

Carol Ann Borchert

University of South Florida, borchert@usf.edu

Follow this and additional works at: https://digitalcommons.usf.edu/tlar_pub

Part of the American Studies Commons, and the Library and Information Science Commons

\section{Scholar Commons Citation}

Borchert, Carol Ann, "Untangling the Jungle of E-Journal Access Issues Using CRM Software" (2006). Academic Resources Faculty and Staff Publications. 5.

https://digitalcommons.usf.edu/tlar_pub/5

This Article is brought to you for free and open access by the Tampa Library at Digital Commons @ University of South Florida. It has been accepted for inclusion in Academic Resources Faculty and Staff Publications by an authorized administrator of Digital Commons @ University of South Florida. For more information, please contact digitalcommons@usf.edu. 
Untangling the Jungle of E-Journal Access Issues Using CRM Software

Carol Ann Borchert, University of South Florida

\section{$\underline{\text { Abstract }}$}

Librarians have been struggling for years with the variety of issues arising while troubleshooting access to electronic journals. This article outlines the advantages and disadvantages of using a Customer Relations Management (CRM) software, originally designed for a call center, to communicate with patrons and track access issues. Utilizing the email software used by the Reference Department at the University of South Florida, we assign incidents, correspond with patrons and staff, write internal notes, maintain transactions, and pull statistics. Hopefully, library vendors will develop software oriented to the needs of libraries to assist in managing access problems for e-journals.

$\underline{\text { Introduction }}$

As journals move into an online environment, librarians managing access to these titles encounter difficulties at a number of points. In the print environment, we checked in an issue and sent it to the shelf. Later it would be bound with others, but, for the most part, we could be reasonably sure that it would always be there.

Online titles present many new complications. If the publisher changes, so does the platform. We then need to determine if we will still have access to our previous issues, and if so, under which publisher, whether we need a license agreement, and whether and how to register the title again with the new publisher. Though we could 
view an article yesterday, there is no guarantee we will be able to access that content next week. When a patron complains, we must determine if it was a problem with the user, the library, the link resolver, the publisher, the subscription agent, the vendor managing the publisher's content, the database from which the citation was found, or the proxy database. Access problems can also be caused by an Internet glitch, firewalls preventing proxy access, outdated software versions, or incompatible browsers.

\section{Barbara Schader published a case study in E-Serials Collection Management} outlining the many problems that librarians encounter while trying to solve access problems for patrons. She lists the various categories of access issues:

- When back issues are accessible, but not the current issue(s)

- When volumes, issues or articles are missing

- When there is no subscription, or it is on hold, or expired (or about to expire), or patrons are being asked to enter a user name and password, or to pay for viewing content

- When access to full text is available but has not been activated

- When a site demands a user name/password

- When IP addresses are not registered on the providers' servers

- When a site's domain is not registered to the proxy server

- Patrons' Web browser is not configured to use the proxy server

- When providers' servers are unavailable

- When maximum number of concurrent users is reached

- When records contain incorrect URLs or URLs that lead to journal sites that do not link to actual content 
- When full text is available in .pdf format, but patron does not have reader and/or has difficulty downloading/installing the reader

- When access to full text in .pdf format is denied (2004, p. 148-155)

Schader also outlined the steps and thought processes her institution, the UCLA Biomedical Library, follows to solve these issues. UCLA is using an Electronic Resource database created in-house to manage and track problem reports. Some of the new Electronic Resource Management systems have an option to track incidents related to publishers or packages. As noted above, access problems cover a wide spectrum of issues, which highlight some of the reasons for the frustrations of e-resource managers and serials librarians, and why e-journals are so complex (as if the print was not complex enough). The job of any e-resource manager involves this sort of problem-solving. Sometimes, the answer might be as simple as assisting the patron by interpreting the information screens. (This begs the question of why such screens would need interpretation, but that is it the topic of another article.) More often, the source of the issue lies outside the library's control, placing the librarian in the position of liaison between patron and publisher, or patron and systems department.

\section{The University of South Florida}

The University of South Florida (USF), founded in 1956, is a single university, geographically dispersed, having locations in Tampa, St. Petersburg, Sarasota, and Lakeland, with Tampa being the largest campus. We share one set of IP addresses, and electronic resources are administered from the USF Tampa Library. USF began using SFX from Ex Libris as a link resolver to provide ready access to our electronic 
journals in July 2003. Remote users are authenticated by IP address through a proxy server or through BlackBoard. When we first started using SFX, our knowledge base was not complete, and we have spent many staff hours ensuring that the thresholds in SFX reflect the access for our university.

Prior to implementing SFX, we added links to the bibliographic records for periodicals to indicate which databases provided access. With over 7,000 subscriptions, not including the 13,000-plus unduplicated titles in our aggregator databases, keeping these links current was overwhelming. We now include the SFX link in the bibliographic record, so we fix the thresholds or change the database listing in only one place. Because we originally used vendor links in the OPAC records instead of the SFX link, many of our records still have old, often nonfunctioning, links in the bibliographic records. We are working to correct the situation, but it is a time-consuming process. As a result, we often need to know if a patron reached an e-journal screen through a database, through the OPAC, or through the SFX A-Z list in order to troubleshoot a problem.

With the advent of SFX in 2003, we started using a specific email address for staff to report problems accessing e-journals. This created problems, as email messages can be buried in an inbox full of other messages, and, because several people received the email, no one knew when someone else had already responded to it. Also, if we had a pattern of access problems, it was not readily apparent because the old emails were deleted once the immediate problem was handled.

\section{Using Customer Management Software}


A Customer Relations Management (CRM) system can be defined as the "sum of all planning, development and activities needed to create a personal relationship with your customers." ("Getting the Most," 2005, p. 63) As libraries move services into an online environment, there is no reason that librarians in Technical Services should leave all service responsibilities with Public Services staff. Through online forms for reporting problems, we have the opportunity to communicate directly with patrons to help them access information, which means we must be mindful of how we communicate. Patrons are our customers, whether we work in technical services or public services. Tools such as a CRM allow staff in technical services to foster more personal relationships with endusers.

At the suggestion of our Assistant Director for Technology in June 2004, we began using the same CRM software that the Reference Department was using for its patrons as a reporting and resolution system to resolve problems accessing e-journals. The Academic Computing department at USF had been using the RightNow ${ }^{1}$ commercial software for troubleshooting problems reported to their department, and because they had the license and were already providing support and upgrades for that product, they encouraged Reference to piggyback on the existing software already in place. Access Services in the library had also been using this same CRM software to track reports of missing books, requests for holds and recalls, and rush cataloging requests, just to mention a few of the 13 different uses that department has found for CRM software. Originally, rush catalog requests were to be reported through the system to Cataloging, so that department had an existing "incident," or subsection, in RightNow.

\footnotetext{
${ }^{1}$ For more information about the RightNow software, please go to http://www.rightnow.com/.
} 
Because it was not being used at that time, we appropriated it for reporting e-journal access problems.

From the patron's view, there is a publicly accessible Web form requesting a citation and a description of the problem. (See Figure 1. Web form for reporting problems.) This is available in the Online Forms section of our libraries' Web pages and from our SFX service screens. Originally, the link to the form was labeled "Report an SFX problem," which was grossly unfair, because SFX was often the symptom, but not the problem itself. The SFX screen was simply the last screen the patron saw before leaving our Web pages. The title of the form has since been changed to "Report a problem accessing an e-journal." This generates an email through the system which is sent to a group of staff, including the Coordinator for Serials, the Coordinator for Electronic Collections, the E-resources Cataloger, and the Serials Acquisitions staff. Staff members who prefer to use the old email address can do so, and that email is automatically forwarded to the CRM software, so that we receive a notification as if they had filled out the form. Any staff member in Technical Services receiving the email can then sign into the system on Internet Explorer and respond to a problem, or leave a note and assign the issue to another staff member. (See Figure 2. RightNow incident console.) This way, anyone viewing that incident report will know what action, if any, has already been taken. Because other departments are using this same software, we can also assign it to, for instance, someone in Reference if it was really a Reference question and the patron simply used the wrong form to ask the question.

Using a CRM software to manage reports of these problems has produced a number of benefits for us. We can always see when someone has-or has not- 
responded to a staff member or patron's reported problem. The software maintains a searchable record (by incident number, contact person, or summary/thread) of all incidents reported. (See Figure 3. Search screen in RightNow) If a problem sounds familiar, we can search for other reports on that title or vendor to determine a pattern. For instance, in fall 2005, there was a problem reported with how a title was displaying through SFX. After reporting the problem to Ex Libris, I was informed that it would be fixed in the next software version. A month later, when the same problem was reported again by another librarian, I could search for the text of the email I had saved in the note portion of the original incident and forward that information, without having to search through old emails (assuming it had not been deleted) or reporting the problem to Ex Libris a second time. On another occasion, we noticed a pattern of titles not listed in our proxy database, all from the same publisher site. After three or four such incidents were reported, our Assistant Director for Technology pulled a list of URLs for that vendor and made sure all of them were in proxy. Thirty of them were not, and we were able to correct the situation before thirty frustrated patrons reported the problem. This revealed a workflow glitch several months later when we again started getting reports on that same publisher, and we realized that it had not been communicated to Cataloging to send every URL for a new title in that SFX target, or publisher title group, to be added to the proxy database, because each title in the subscription group has a unique URL.

The RightNow software provides statistics on the number of transactions we have solved in a given month, how long it takes to solve an incident, staff activity, and the number of incidents assigned versus the number solved by each person in the group. The most valuable report for us was the number of incidents. (See Figure 4. Statistics report from RightNow.) This has assisted us in tracking the number of 
reported incidents over the past two years. (See Figure 5. Statistics collected from RightNow system, 2004-2006.) The charts in Figure 5 were created in Excel and are based on two years of monthly reports. The number of incidents increased slightly after we made the reporting form more accessible to patrons in May 2005 by adding the link to the reporting form on the SFX services screen. The average number of incidents per month in $2004-2005$ was 17.6 with a mean of 17 ; in the $2006-2007$ fiscal year, the monthly average was 21.7 incidents with a mean of 21 . Unlike Reference, we cannot solve most incidents within a day or so. Because access problem reports often require us to report technical issues to an outside entity, such as the publisher, we have to wait for a response. Also, if the publisher responds, for instance, that the content for an issue is missing, but is expected to be available in two months, we can keep that incident open so that we remember to check and see if the content is there before changing the status from "unresolved" to "solved." As mentioned above, there is a notes section that is only viewable by our staff where we can record responses from vendors on the status of a problem, often rephrasing it for a response directly back to the patron or staff member originating the request for information. This same note field allows us to record internal notes to each other if several of us need to work on the same problem together.

\section{Limits and Disadvantages}

Like any software, this CRM presents some limitations. Because we have to open a Web browser to respond to an issue instead of responding directly to the email we receive, it takes a bit longer. If we do respond to the original email, it creates a new incident report in the system, which can be messy. We have the ability to add a new incident if we receive information directly by phone call or an individual email, which 
takes time to transcribe. In our most recent software upgrade, that process became considerably more complex. Transcribing an incident, however, allows it to be reported as part of our statistics and be searched later if needed. As discussed previously, the statistics have some limitations for the purpose for which we use the system. RightNow was designed as a call-center software, so the statistics reflect a high-volume, fast turnaround environment. In giving credit for who solved a problem, it is only assigned to the person who last touched it. It does not take into account whether several people may have been involved in solving an issue. Also, once we send a response to a patron, the status automatically sets itself to "waiting" instead of "unresolved," thus removing it from the immediate display. Because we would have to do a separate search to find incidents with a status of "waiting," those incidents could easily be forgotten. As a result, we try to reset the status to "unresolved" before saving the patron response.

\section{Responding to Patron Submissions in the System}

Using a CRM in Technical Services allows us direct access to the patron. We do have to be careful, as do our Public Services colleagues, to avoid the "ping-pong" effect of shuttling patrons from one department to another. When referring a patron to another department, that department may refer the patron back to us. Schader makes an excellent observation on this matter: "How we handle our response to their [the patrons'] problems may be the only information they have available for forming their opinion of a library staff's competence and value." (2004, p. 141) This is a warning worth heeding. 
As with any email or online service that interacts with patrons, staff must be cognizant of how the written word is interpreted by the reader. We lack the contextual clues we would obtain in a face-to-face or even a phone interaction such as expression and tone of voice. Responses to patrons and staff are in some sense like conducting a reference interview in writing. People skills, typing skills, and written communication skills are a must when working with a CRM to manage access issues, particularly when patrons are able to contact technical services staff directly. Staff should carefully and courteously phrase their responses, and use emoticons as necessary to indicate their actual tone. In technical services, many of us are accustomed to providing terse, efficient responses while we are focused on the mechanics of solving a problem. This works well in a department of people who know each other, but patrons appreciate the effort to project a friendlier tone in responding.

We need to know when to pick up the phone if written communication is not effective. This is not always possible, as patrons do not have to provide phone contact information when reporting a problem through our Web form. However, if the problem is reported by a staff or university faculty member, they often provide a phone number or one is readily available. In any case, responding to the patron immediately in some form is important. Communicate the time frame for solving the problem if possible, and what action has been or will be taken. The CRM that we use produces an autoresponse when an incident is reported indicating that someone will respond within 24 hours. The Coordinator for Serials and the E-resources Cataloger are usually the first people to view the incident and assign it to other staff as needed. If one or both of them are on vacation, other staff members need to be aware of that in order to monitor the system more closely. 
When viewing an incident, we need to determine if the problem is one of recordkeeping at our institution, if it is a vendor problem, an access issue, or a technical problem at our end, the publisher's end, or the patron's end. If we are able to access the material inside the building, we need to know if the patron is using EZProxy or BlackBoard to access the material, which browser they are using, the exact error message they are receiving and at what point, and, if it is a problem accessing a .pdf file, what version of Adobe Acrobat they are using. If we cannot resolve the problem in a timely manner, we make notes in our system and refer the patron to interlibrary loan for faster service while we continue to troubleshoot the issue. If we notice that we are giving the same type of response to several questions, we can set up standard text in the system to save time on typing, then edit the text for the specific complaint.

\section{Selecting a System}

Although our situation was unique in that our Academic Computing department selected the software for us, there are a number of factors to keep in mind when selecting a CRM to use for troubleshooting serials access issues. If your public services department has a similar system already in place, it would be worth investigating to see if the same software would have application for serials issues, or for other aspects of technical services. Try searching for articles on customer service software or customer relationship management (CRM) software in Google or in business databases. There are several articles in the library literature which discuss chat software used by reference that has an email component. Jana Smith Ronan published a book on chat software in 2003, Chat Reference: A Guide to Live Virtual Reference Services. The book provides 
in-depth descriptions of several software packages and descriptions of call center software in general.

Harney describes a CRM as "the process of combining a company's best business practices, optimized work processes, appropriate technology, and relevant knowledge to service customers better and retain their business." (2003, p. 32) Adding an additional software system such as this involves time training staff, consideration of how it fits into existing workflows and many other factors. For the University of South Florida, using this software versus a direct email has solved several issues, while creating some minor issues along the way. The benefits, however, have far outweighed the disadvantages for us. Implementing such a system can create more problems than it solves, and librarians must be careful of that pitfall. The functionality of a new system should enable our processes, not drive them. (Rosenberg, 2004) With some exceptions, much of the CRM software available has been designed for businesses, not for libraries. In moving this software into a library environment, we need to carefully consider how it facilitates (or complicates) what we are already doing. Given enough demand, some of our library vendors may develop such software specifically for library use. Some vendors and publishers, such as Ex Libris and Wiley, have started using CRM systems themselves to manage technical support questions from their customers.

\section{Functionality}

When evaluating new software, there are several considerations to keep in mind. Take time to draft a picture of what the ideal software would be able to do for you. Because no single software will be able to accomplish that, next focus on the key 
characteristics you need. Be involved in deciding which software to use, and compare the pros and cons of several products. Ideally, the vendor will provide the opportunity for a trial or demo version of the software.

Determine if other departments in the library can use the software, and if so, how. Finding multiple uses makes a case for purchase to the administration. If you are going to share it with your reference department, does the system have both email and chat functionality? There may be an option to create an FAQ database for patrons to search or browse previously commonly asked questions, so determine if you have a use for that feature.

If the system has the ability to search and find information based on previous incident reports, how is that information arranged and retrieved? Unfortunately, in our system, our subject lines are as inconsistent as if the report had come by email. Staff have the option of changing the subject line to make them consistent, but we have been woefully negligent in remembering to do that. Also, decide what, if any, types of statistics you hope to be able to retrieve from the system. Make sure that the software is not counting email spam in your statistics if, as in our situation, it is possible to send an email to report a problem.

Cost

Obviously, cost will be a significant factor for most institutions. Bear in mind that the initial cost is only one aspect. There may be ongoing expenses, such as maintenance contracts or system upgrades. System upgrades are not always a good 
thing, so don't move to a newer version unless it is going to be an improvement for you. To possibly reduce costs, find out if the software can be purchased in modules. For instance, you may need to use it for email responses, but may not need the chat feature.

Consider whether to host the software locally or not, and the costs involved in each option. Keep in mind the cost of installation and configuration services. Jason Compton, in his article "How to ... negotiate a CRM engagement," states that "One of the best-kept secrets of the software business is that the real money is made after the initial sale-in the form of installation and configuration services and annual maintenance contracts." (2005, p. 54) Compton also recommends having a contract expert carefully evaluate each line of the agreement to avoid any hidden surprises.

\section{Vendor support}

Find out what type of support the vendor offers, such as onsite training, tutorials, documentation, or general technical support. Determine if the library or vendor are responsible for implementing software upgrades. Not only do you need to be cognizant of the reliability and response time of the system itself, but of the vendor's reliability and response time in resolving a problem.

\section{Usability}

Usability for both patrons and staff is important. Make sure that instructions and help features are available if needed. Even better, find a system that has a friendly and intuitive user and staff interface that is easy to navigate. For instance, call center 
software tends to have a Web-based interface. Avoid systems that require the patron to download additional software.

Librarians may want to be able to create canned or pre-programmed answers for common questions to save on typing time. The ability to reassign or transfer an incident to another librarian if needed is also useful. Some systems provide spell checker features.

Consider whether staff members can administer the system from any computer, whether in the office or at home. Because many of our patrons are accessing e-journals from off-campus, we cannot duplicate the problem from within the building. I have occasionally been able to better troubleshoot an incident from my home computer, then go into the system and respond to the patron from home.

\section{System Requirements}

There are a number of system requirements to consider in purchasing a CRM software, such as whether it is compatible with multiple operating systems, what sort of network infrastructure is required, whether staff need additional software installed, and how much RAM and bandwidth are needed to run the software. As with any system, speed, efficiency, reliability, and effectiveness are all important. If applicable, is the CRM software compatible with the institution's existing email system, and is the system housed on the library's servers or the vendor's?

\section{$\underline{\text { Conclusions }}$}


Managing online access to serials is a complicated endeavor with opportunities for problems at a myriad of points in the system. The University of South Florida has found the use of Customer Relations Management software to be helpful in tracking problems with access to e-journals. As with any online form, we have patrons reporting a wide variety of issues, but overall this has helped us document and track the types of access problems we have with e-journals. We can only hope that vendors specializing in services to libraries will in the future create more software options to assist us in tracking the information collected while troubleshooting access to our electronic journals. 


\section{References}

Compton, J. (2005) How to ... negotiate a CRM engagement. CRM Magazine. 9 (3), 54. Retrieved April 15, 2005 from InfoTrac OneFile database.

Getting the most out of CRM Technology. (2005) Travel Weekly. 64 (13), 63. Retrieved April 15, 2005 from InfoTrac OneFile database.

Harney, J. (2003) Personalization and CRM: Know Thy Customer. AlIM E-Doc Magazine. 17 (4), 32,33-36. Retrieved August 26, 2006 from ABI/Inform Global database.

Rosenberg, A. (2004) Which CRM is Right for You? Call Center Magazine. 17 (12), 28-38. Retrieved August 26, 2006 from ABI/Inform Global database.

Schader, B. (2004). Case Study in Claiming/Troubleshooting E-Journals: UCLA's Louise M. Darling Biomedical Library. In D. C. Fowler (Ed.), ESerials Collection Management: Transitions, Trends, and Technicalities (pp. 139-158). New York: Haworth. 
Connect from Home Online Renewal Ask-a-Librarian Giving Opportunities

USF > USF Libraries > Report a problem accessing an e-Journal

Report a problem accessing an e-Journal
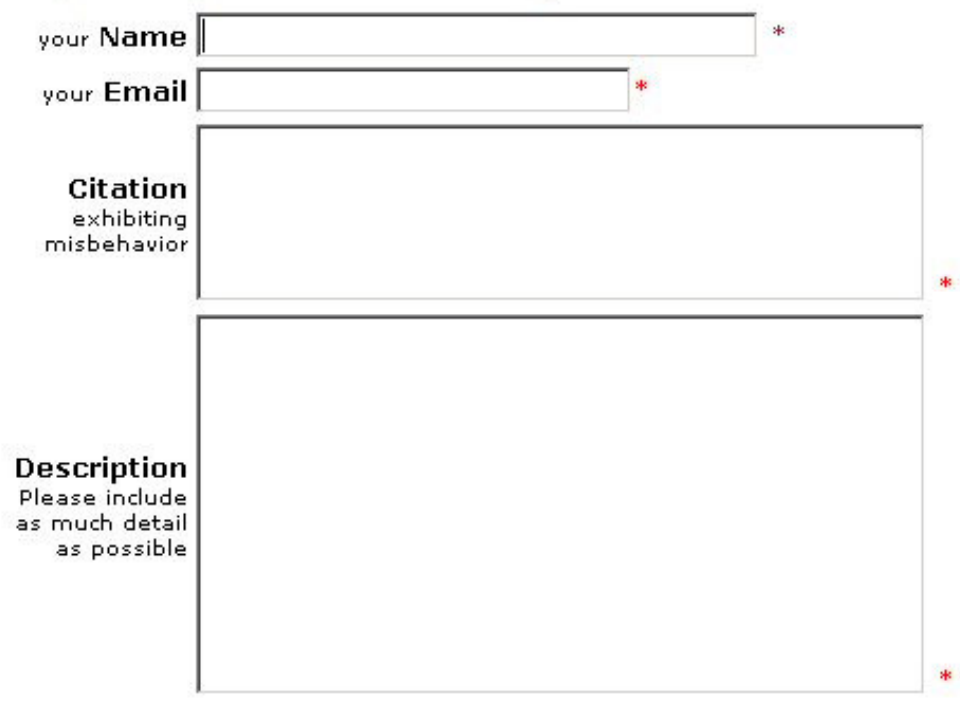

* Required Fields

\section{Send the Request Clear the Form}

Copyright 2004, University of South Florida Libraries, Administrative Offices, 4202 E. Fowler Avenue, LIB122, Tampa, FL 33620 . For technical assistance, suggestions, or comments, please contact us.

Figure 1. Publicly accessible Web form for reporting problems. 


\section{Reference \#}

060829-000574

Primary Contact

no name

borcherticlib.ust.edu

No Organization

- Status

Unresolved

Assigned

LIB CAT

- LIB Carol Anп Borchert

- Category

- Library

- Cat SFX Issues
19

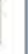

1

\section{\begin{tabular}{l|l|l|l|} 
Messages Details Organization & Contact \\
\hline
\end{tabular} \\ - Subject SFX Problem reported by Mary Sinith}

\section{Customer}

SFX Problem reported by Mary Sinith

Reported by: Mary Sinith

Email: borchert@lib.ust.edu

Citation that will demonstrate problem:

American Journal of Community Psychology, v. 37, no. 3/4, p. 191 ,

title: Engaging Diversity's Underbelly: A Story from an Immigrant Parish Community

Author: Borg, Mark

Description of Problem:

I am unable to access this article

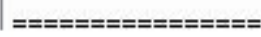

Add

C Customer Entry

c Response

느ote

Standard Text...

Suggestions...

Search...

\begin{tabular}{c}
\hline Quick Texxt... \\
\hline Quick Answer... \\
\hline
\end{tabular}

Thanks so much!
I am able to access this article from within the library. Could you please provide more information about the error message you are

receiving? Specifically:

--if you are receiving an error message, please provide as much detail as possible about the content of the message and at what point you

are receiving it (i.e., can you get into the database or journal, is it asking for a username and password, etc.)?

--what type of browser are you using (Internet Explorer, Firefox, other)?

--are you accessing the library's resources through EZProxy or Elackboard?

-if the resource is leading you to a .pdf file, which version of Adobe Acrobat do you have loaded on your machine?

Please provide the aforementioned additional information so that we can further troubleshoot your problem.

Carol Anח
08/29/2006 05:05 PM 


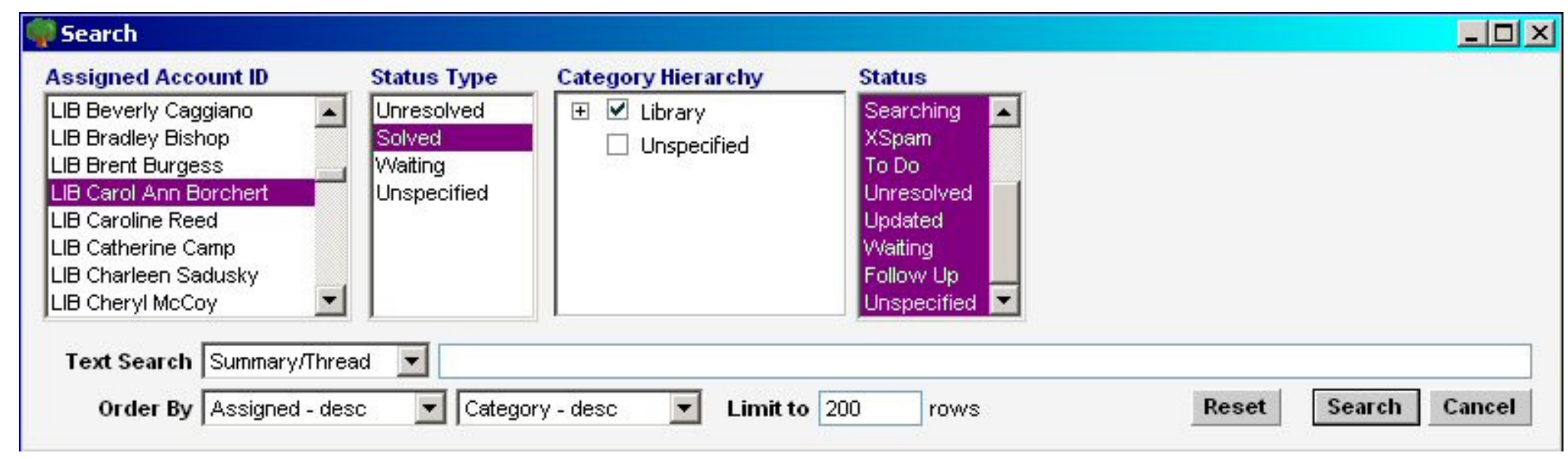

Figure 3. Search screen in RightNow. 


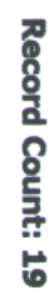

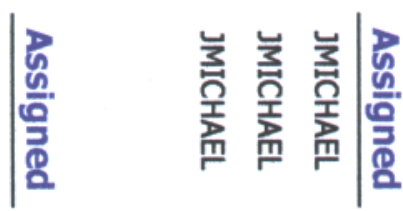

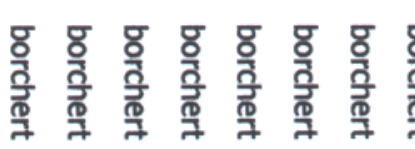

II

然

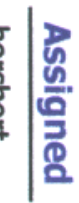

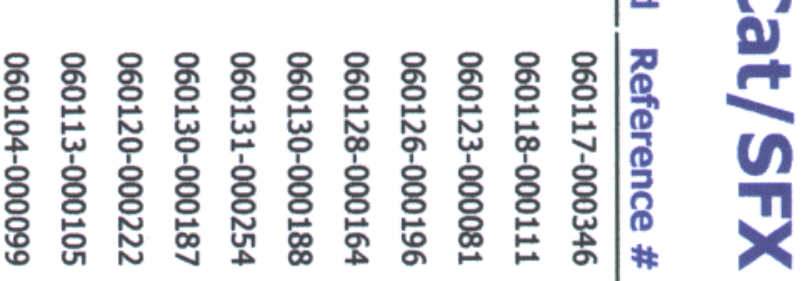

店客各造

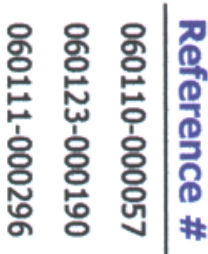

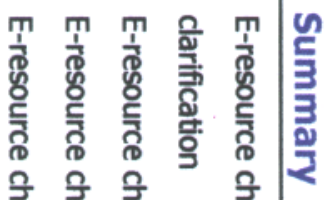

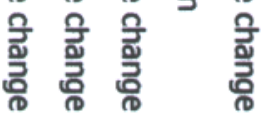

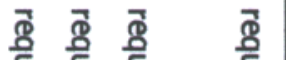

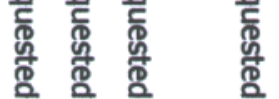

प श श

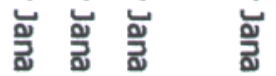

$\pi$

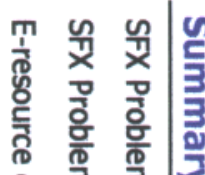

当当

产

串

ट्रे प

兽急

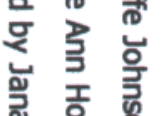

질

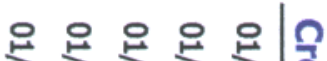

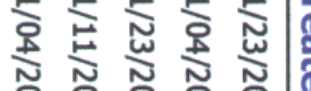

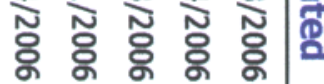

운

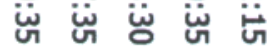

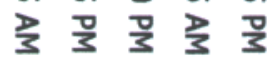

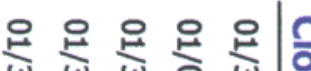
ખ્ 뻥 오

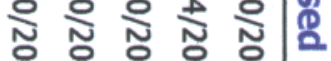

ठㅇㅇㅇㅇㅇㅇㅇㅇㅇㅇ

안ㅇㅇㅇㅛ

飠

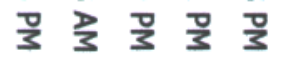

जิ

อ

竍
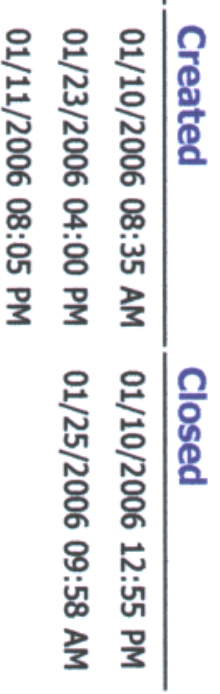

$\stackrel{\omega}{\mathbf{6}}$
鹤 旁

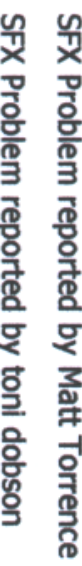

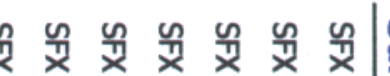

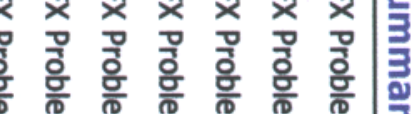

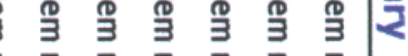

蛋 蛋

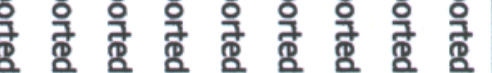

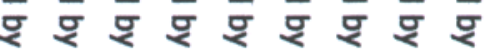

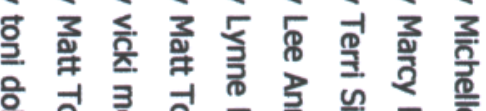

옥

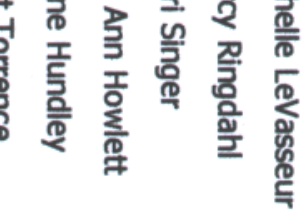

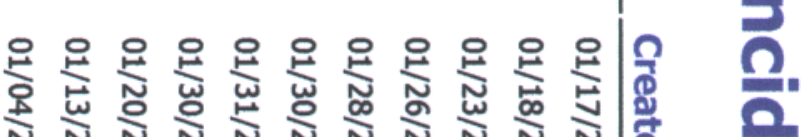

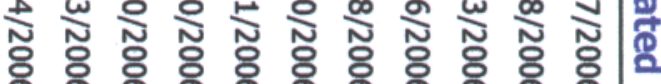

\&

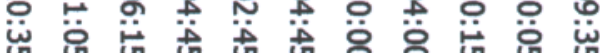

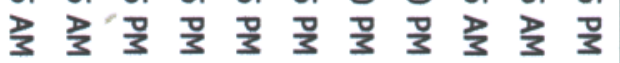

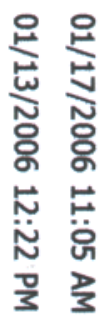

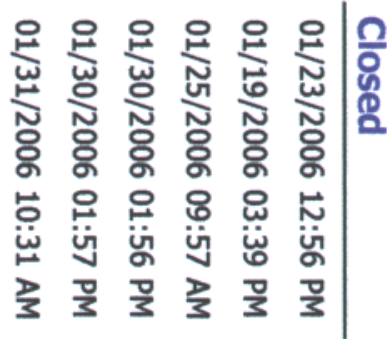



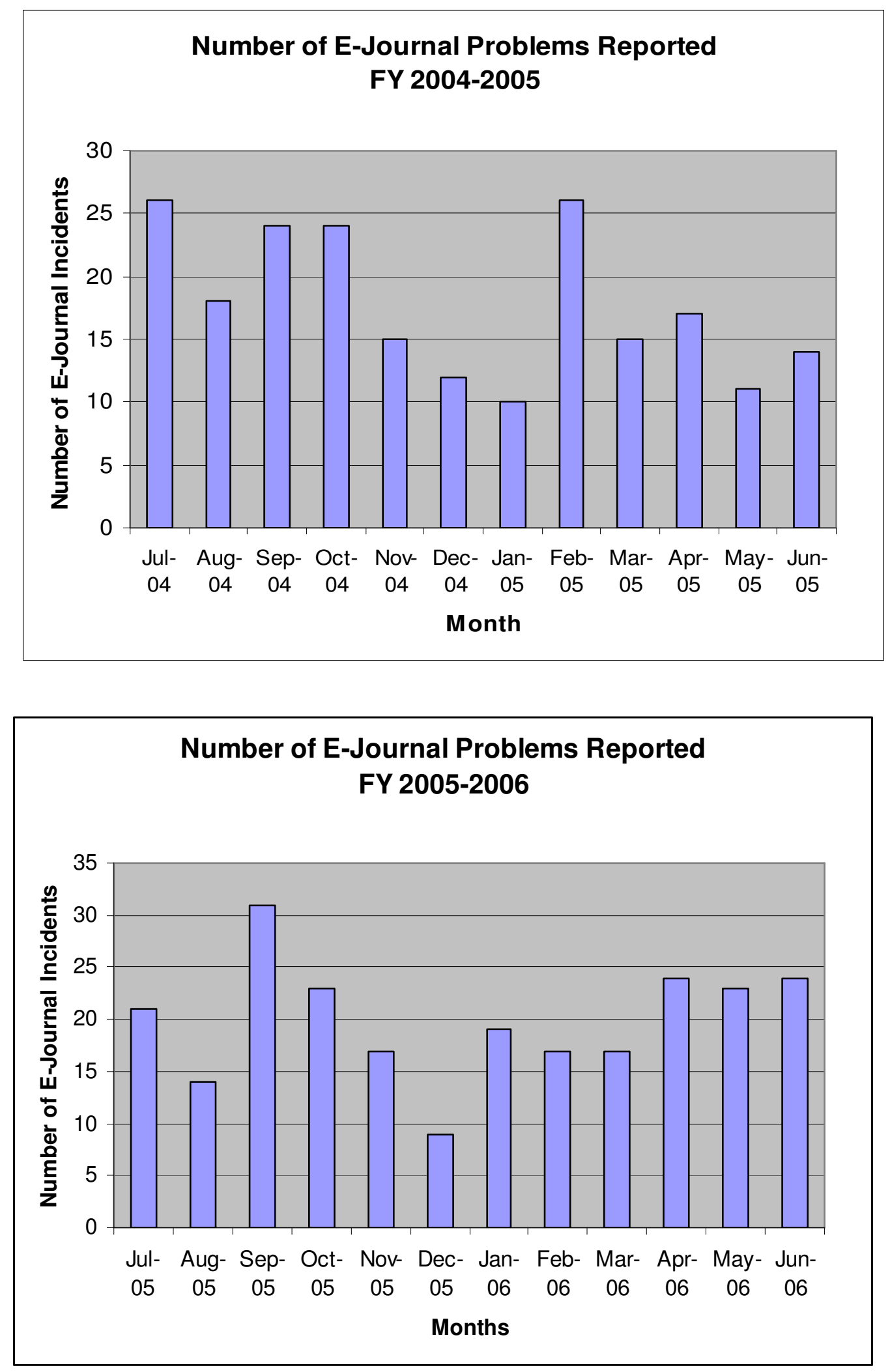

Figure 5. Statistics collected from RightNow system, 2004-2006. 